\title{
Research on the Impact of Customer Participation on Their Satisfaction Under the Background of Value Co- Creation
} — Taking Smartphones as an Example

Xiaoyu Zhao*

\author{
Beijing Jiaotong University \\ *Corresponding author.Email: zxyhebuter@163.com
}

\begin{abstract}
From the perspective of value co-creation, customers become value co-creators. Many companies encourage customer participation in order to create value and improve satisfaction, but at present there is no consensus on whether customer participation will lead to customer satisfaction. This article uses smart phones as an example to answer the impact of different types of customer participation in value co-creation behavior on their satisfaction through three sets of scenario simulation experiments. The research results show that Information-providing customer participation has the smallest increase in satisfaction, cooperative development is moderate, and joint decision-making improved the largest extent, this article provides empirical evidence for exploring the relationship between customer participation in value co-creation and satisfaction.
\end{abstract}

Keywords: Value co-creation, Customer participation, Customer satisfaction, Smart phone.

\section{INTRODUCTION}

Traditional marketing theory believes that the enterprise is the original creator of value, and the customer is only the passive receiver of value. In recent years, service-dominant logic has been proposed. It believes that the core of marketing activities is interaction with customers. The knowledge and skills possessed by customers become manipulative resources, and customers become value co-creators besides the enterprise. Value co-creation provides a new path and interpretation for the value creation process.

At present, customer participation in the co-creation of corporate value has become a popular trend. Customers can participate in various value creation processes such as enterprise design, production and sales, and obtain final products that are more in line with their expectations. Enterprises can also reap unexpected profit growth through the value co-creation mechanism. Therefore, in recent years, many companies have begun to attach importance to and encourage customer participation in order to clarify customer needs, bring customer satisfaction, and better create customer value, thereby enhancing corporate competitiveness.

But does customer participation necessarily lead to customer satisfaction? Some scholars believe that after participating in the corporate value co-creation process of product development or service innovation, customers will have a better understanding of product attributes and service content, and their expectations for product or service quality will be more realistic, shortening the gap with the original perception, so it can increase customer satisfaction. However, some scholars believe that customer participation in the co-creation of corporate value may not necessarily bring customer satisfaction. Zhang showed through experimental methods that if customers overestimate the influence of participation behavior on the results, and the actual results are inconsistent with expectations, it will cause a significant decrease in customer satisfaction. Therefore, in the current research results, there are still differences in the results of customer participation on customer satisfaction.

Under the background of value co-creation, the role of customers has changed, and participation behavior has gradually shown new characteristics. Nowadays, 
scholars are paying more and more attention to customer participation in enterprise new product development or service innovation. Although the research on customer participation in the field of marketing has a certain foundation, whether customer participation can definitely bring customer satisfaction has not yet reached a consensus. Therefore, research on the impact of customer participation in corporate value co-creation on satisfaction is still a question worth exploring.

\section{THEORETICAL BASIS}

\subsection{Value Co-creation}

The purpose of a business is to create value. Kambil first proposed the term "value co-creation" in 1996, emphasizing the role of customers in creating value in business strategies and marketing, and simply defined "value co-creation" as "the process by which an enterprise and its customers jointly produce value." Then Bendapudi and Leone defined "value coproduction": customers participate in the production and delivery process of products or services and thus obtain customized results. Then Prahalad and Ramaswamy formally summarized the connotation of "value cocreation". They believed that enterprises and customers conduct value creation processes at multiple points of interaction. Later, scholars have expanded the research on the subject of value co-creation. Cova and Salle believe that the process of value co-creation involves participants in the supply network and customer network, and all the participating subjects integrate and interact with resources to create their own value.

\subsection{Customer Participation}

\subsubsection{Customer Participation Definition}

Customer participation was originally regarded as the degree of customer involvement in service production and delivery. The negative impact of customer participation in the service process on the company's revenue was mainly considered from the perspective of the seller. But with the emergence of value co-creation theory, customers have gradually become a heterogeneous resource for corporate value creation, and customer participation has begun to have a positive impact on the production or service process of corporate products. Ritter and Walter believe that customer involvement refers to the degree to which customers give their wisdom and knowledge. Cragin pointed out that customer participation is the degree of customer interaction with the company in the new product development process.

\subsubsection{Customer Participation Dimensions}

The role of customers has changed. Participation behavior has gradually shown new characteristics. Scholars have different ways of dividing customer participation. In order to explore the relationship between customer participation and satisfaction in product innovation, Wang and Luo divided customer participation into information providers and codevelopers. In order to explore the impact of customer participation and customer perception on purchase intention, Liu and others divided customer participation into three types: information sharing, responsible behavior and interpersonal interaction. Based on the perspective of co-creating value, in order to explore the impact of customer participation behavior on satisfaction, customer participation is divided into information sharing, cooperative development and joint decision-making. Combining the above scholars' division of customer participation dimensions, this article divides customer participation into information provision, cooperative development and joint decisionmaking, so as to explore the impact of customer participation behavior on customer satisfaction from the perspective of value creation theory.

\subsection{Customer Satisfaction}

Customer satisfaction refers to the state of pleasure or disappointment formed by comparing the inner perception effect of the customer after using the product or service with the expected expectation before the purchase and use. Customer satisfaction depends not only on the product or service result itself, but also on the product or service delivery process. From the perspective of value co-creation, customers, as value cocreators, participate in the process of product or service generation and the delivery process, so their satisfaction is often used as a result variable to judge the effect of value co-creation. For example, Óscar through research on hotel brand value, proved that if customers can perceive the process of hotel value co-creation, customer satisfaction will increase. In summary, the literature on customer satisfaction in value co-creation is very rich, but the relationship of action is still unclear. Therefore, this article discusses the impact of customer participation in value co-creation on customer satisfaction still has theoretical and practical significance.

\section{RESEARCH HYPOTHESIS}

\subsection{Information Provision}

Information provision means that customers continuously transfer their own knowledge, emotions, ideas, skills and other information related to value creation to the enterprise, and exchange information 
with the enterprise. Continuous, two-way and interactive "dialogue" is the basis for customers as information providers to participate in the process of enterprise value creation. These characteristics reflect that customers have the same equality as the enterprise. Customers transfer their own knowledge, skills and information to the company, and the created products will be integrated into the customer's own ideas and ideas, and customers will have a stronger perception of the products provided by the company.

Therefore, hypothesis $\mathrm{H} 1$ is put forward: customers as information providers participate in the value cocreation will improve their satisfaction.

\subsection{Cooperative Development}

Cooperative development is where customers participate in the value creation process by investing in manipulative resources. In an environment of mutual coordination with the enterprise, customers and their knowledge and skills have become manipulative resources. Cooperative development and participation methods are more creative, because customers take the initiative to invest. Through personal participation, you will have a deeper understanding of products and services. Product development with the help and guidance of the company can distinguish the quality of the products before and after the participation.

Therefore, hypothesis $\mathrm{H} 2$ is proposed: customers as co-developers participating in value co-creation will increase their satisfaction.

\subsection{Joint Decision}

Joint decision-making is a form in which customers discuss problems and make decisions on solutions. The participation form of "joint decision-making" enables enterprises to authorize customers, and customers can choose and make decisions on the field of participation, the content of participation and the way of participation, which reflects the basic characteristics of co-creating value. The customer obtains greater choice, control and decision-making power over the internal affairs of the enterprise.

Therefore, Hypothesis H3 is proposed: Customers as joint decision-makers participate in value co-creation will enhance their satisfaction.

\subsection{The Degree of Influence of the Three Participation Methods on Satisfaction}

Since information-providing customer participation only provides relevant opinions and does not directly participate in product development, the participants have a relatively small impact on product performance perception before and after participation. Participants of cooperative behavioral customer participation directly participate in product development and design, and the product performance has changed to a certain extent after participation. However, due to the limited level of knowledge, it is impossible to implement more confident control over the development process, so the participants' perception of product performance is not the largest increase after participation. The joint decision-making customer participation can have greater decision-making power on many issues in the product development process, so the perception of the product has been the most obvious improvement after participation, and because the problems in the development process are all With solutions, joint decision-making subjects just compare several solutions and decide which one they think is the most satisfactory, and they will feel more satisfied with the new products they develop.

Therefore, hypothesis $\mathrm{H} 4$ is proposed: three types of customer participation can improve customer satisfaction, among which information-providing customer participation has the lowest increase, cooperative development has a medium increase, and joint decision-making has the highest increase.

\section{EXPERIMENTAL DESIGN}

Considering the popularization effect of smart phones in the era of mobile internet, most customers have the experience of using smart phones, and the products of smart phones are rich in content, which is convenient for investigation. Therefore, this study uses smart phones as the research object. The experiment takes the virtual mobile phone brand company to respond to market demand and invite customers to participate in the company's new mobile phone development process as the background. Choosing a virtual brand can eliminate the participant's error in the original perception of the mobile phone brand, and can be more involved in the experimental situation and reduce the interference of the mobile phone brand.

This experiment is carried out with the help of the voice call function and document presentation function of the enterprise WeChat platform. At most 5 students are invited to participate in the experiment at a time to ensure that the network is unblocked and the experiment process is controllable. Through voice description and document context display, conduct context experiments and retrieve data results for analysis. The question items in the experiment choose 4 kinds of perceptibility indicators of the smartphone for the subjects to choose.

\subsection{Experiment 1}

After the participant was invited to join, the public document showed the contents of the questionnaire shown in Table 1, and the participant was told to record his satisfaction with several indicators of his mobile 
phone. The entire scale adopts the Likert 5-point scale method, with 1-5 representing five semantic judgments

Table 1. Question of the questionnaire from "very dissatisfied" to "very satisfied".(Table 1)

\begin{tabular}{|c|c|}
\hline Evaluation index & Question \\
\hline A1Core attributes, & How do you feel about the online shopping and secure payment functions of your mobile phone? \\
\hline A2Quality attributes & How do you feel about the configuration and processor of your mobile phone? \\
\hline A3Market attributes & How do you feel about the price/performance ratio of your mobile phone? \\
\hline A4Appearance attributes & How do you feel about the packaging your phone has? \\
\hline
\end{tabular}

After that, the document demonstrated three mobile phone pictures, informing the subject that the mobile phone company he used had invited him to participate in the company's new mobile phone development process in order to respond to market demand. The company's final mobile phone will refer to its design opinions. Three colors of mobile phones were exhibited in the document presentation, and participants were asked to describe their needs for mobile phone colors and give their reference opinions on mobile phone colors. During this process, there was continuous information exchange with the participants. , Discuss how to design colors that customers are satisfied with during the development of mobile phones, so that participants can continuously give information.

After the above operations, the subjects were asked to select the role they played in the process of customer participation in the development of new mobile phones in the enterprise and record the selected answers. The answer is divided into three options: "A information provider, B co-developer, and $\mathrm{C}$ joint decision maker". The correct answer to this question should be A. This question is to test whether the participant correctly understands the purpose of the experiment, and invalid questionnaire answers can be excluded based on this question to ensure the accuracy of the experiment results.

Finally, the document showed the color picture of the mobile phone with the most information given by the participants through the discussion, and told the participants that this was a new mobile phone produced based on their opinions, and asked them to judge the following description of the new mobile phone and record the answer.

After collecting and analyzing the data of experiment one, removing the 3 wrong results of customer participation role selection, a total of 57 valid data were received. Average the scores of each question in questionnaire 1 and questionnaire 2. (Table 2)
Table 2. Experiment 1 data

\begin{tabular}{|c|c|c|c|c|}
\hline & $\begin{array}{c}\text { A1 } \\
\text { Score }\end{array}$ & $\begin{array}{c}\text { A2 } \\
\text { Score }\end{array}$ & $\begin{array}{c}\text { A3 } \\
\text { Score }\end{array}$ & $\begin{array}{c}\text { A4 } \\
\text { Score }\end{array}$ \\
\hline Questionnaire 1 & 4.11 & 3.59 & 4.10 & 3.70 \\
\hline Questionnaire 2 & 4.25 & 3.76 & 4.25 & 4.23 \\
\hline $\begin{array}{c}\text { Satisfaction } \\
\text { comparison }\end{array}$ & +0.14 & +0.17 & +0.15 & +0.53 \\
\hline
\end{tabular}

Perform hypothesis testing on the data. For example, the average A1 score $\mu 1$ in questionnaire 1 is 4.11 , and the average $\mathrm{A} 2$ score $\mu 2$ in questionnaire 2 is 4.25 , and the significance level is $\alpha=0.05$. Since the variance is unknown, a t-test is performed. Use SPSS to perform a paired-sample t-test on the data, test significance $P$ is less than 0.05, reject the null hypothesis, and believe that after customers participate in value co-creation as information providers, they have a significant impact on the satisfaction of smartphone core attributes. In the same way, the other three attributes were tested, and consistent results were obtained, that is, customers participating in value co-creation as information providers will increase satisfaction. Assume that $\mathrm{H} 1$ is verified.

\subsection{Experiment 2}

First, fill in the satisfaction questionnaire 1. Then, during the experiment, the participants were invited to try to design their favorite mobile phone screen style. Throughout the process, the subjects also draw and design their own preferred screen patterns. The subjects will design and develop screen styles that meet their needs according to their desired styles and functions. After the experimental scenario is simulated, the participant is asked to select the role he played in the process of the customer's participation. After that, the document showed the screen style designed by the subjects, and told the subjects that the company produced a batch of new mobile phones based on the products designed and developed by them, and asked them to judge the following descriptions of the newly produced mobile phones. Record the answer. After collecting and analyzing the data of experiment two, 
removing the 2 results of the wrong customer participation role selection, a total of 58 valid data were received. (Table 3)

Table 3. Experiment 2 data

\begin{tabular}{|c|c|c|c|c|}
\hline & $\begin{array}{c}\text { A1 } \\
\text { Score }\end{array}$ & $\begin{array}{c}\text { A2 } \\
\text { Score }\end{array}$ & $\begin{array}{c}\text { A3 } \\
\text { Score }\end{array}$ & $\begin{array}{c}\text { A4 } \\
\text { Score }\end{array}$ \\
\hline Questionnaire 1 & 4.01 & 3.82 & 3.88 & 3.5 \\
\hline Questionnaire 2 & 4.17 & 4.08 & 4.05 & 4.1 \\
\hline $\begin{array}{c}\text { Satisfaction } \\
\text { comparison }\end{array}$ & +0.16 & +0.26 & +0.17 & +0.6 \\
\hline
\end{tabular}

The SPSS is also used to perform paired t-test on the data. The $\mathrm{P}$ values of the 4 mobile phone attributes are all less than 0.05 , indicating that cooperative development customer participation has a significant impact on the satisfaction of the 4 mobile phone attributes, that is, the customer is participating in the mobile development process as a cooperative developer. Later, satisfaction with the use value of smart phones has improved. Assume that $\mathrm{H} 2$ is verified.

\subsection{Experiment 3}

Participants were invited to fill in their perceptions of satisfaction at first. After that, the document showed two mobile phone packaging with different patterns. The participant was asked to comprehensively consider a variety of factors to make a decision, discuss a variety of "solutions" with him, and let him make the final choice and decision making. Participants were informed that apart from choosing packaging styles, they had the right to choose, control, and make decisions about the final mass-produced mobile phone model and other attributes. After the simulation of the experimental situation, the subjects were asked to choose their role. Finally, the document showed the packaging style decided by the participant, and informed him that the company finally produced a batch of new mobile phones according to his decision, and asked him to rate the following description of the new mobile phones produced by the company.

Table 4. Experiment 3 data

\begin{tabular}{|c|c|c|c|c|}
\hline & $\begin{array}{c}\text { A1 } \\
\text { Score }\end{array}$ & $\begin{array}{c}\text { A2 } \\
\text { Score }\end{array}$ & $\begin{array}{c}\text { A3 } \\
\text { Score }\end{array}$ & $\begin{array}{c}\text { A4 } \\
\text { Score }\end{array}$ \\
\hline Questionnaire 1 & 3.91 & 3.45 & 3.55 & 3.41 \\
\hline Questionnaire 2 & 4.09 & 3.95 & 3.91 & 4.05 \\
\hline $\begin{array}{c}\text { Satisfaction } \\
\text { comparison }\end{array}$ & +0.18 & +0.5 & +0.36 & +0.64 \\
\hline
\end{tabular}

After collecting and analyzing the data of experiment three (Table 4), removing the 2 wrong results of the customer participation role selection, a total of 58 valid data were received. The paired t-test was also performed on the data using SPSS, and the P values of the four attributes were all less than 0.05 . It shows after customers participate in the mobile phone development process as a joint decision maker, their satisfaction with smartphones has increased. Assume that $\mathrm{H} 3$ is verified.

\subsection{Experimental Conclusions}

After collecting the data of the three experiments, the comparison results of the perception of each experiment are listed in the table 5.

Table 5. Three Experiments data

\begin{tabular}{|c|c|c|c|c|}
\hline & $\mathrm{A} 1$ & $\mathrm{~A} 2$ & $\mathrm{~A} 3$ & $\mathrm{~A} 4$ \\
\hline $\begin{array}{c}\text { Information } \\
\text { provision }\end{array}$ & +0.14 & +0.17 & +0.15 & +0.53 \\
\hline $\begin{array}{c}\text { Cooperative } \\
\text { behavior }\end{array}$ & +0.16 & +0.26 & +0.17 & +0.6 \\
\hline Joint decision & +0.18 & +0.5 & +0.36 & +0.64 \\
\hline
\end{tabular}

It can be seen from the table 5 that the three different customer participation methods have improved satisfaction perception, and the three customer participation methods are different, and the degree of satisfaction improvement is also different. The information-providing type has the smallest improvement, the cooperative development type is medium, and the joint decision-making customer participation has the largest increase in the use value perception. Assume that $\mathrm{H} 4$ is verified.

\section{CONCLUSION}

Although there have been many studies on customer participation in value co-creation, whether customer participation will definitely lead to customer satisfaction has not formed a consensus among the existing research conclusions. In this paper, three sets of virtual mobile phone brand scenario simulation experiments are used to analyze the impact of three different types of customer participation in smart phone value co-creation behavior on satisfaction with information-providing, cooperative development and joint decision-making. The results of this paper show that customer participation does have a certain impact on customer satisfaction, but different ways of participation have different satisfaction enhancement effects. Informationproviding customer participation has the smallest increase in satisfaction, cooperative development is moderate, and joint decision-making improved the largest amplitude.

\subsection{Management Enlightenment}

There are certain prerequisites for whether customer participation in value co-creation will bring customer satisfaction. There are also many examples of customer dissatisfaction caused by customer participation in value co-creation. For example, in the mobile phone development process, if people who do not have the knowledge and interest in mobile phone development are involved, customer satisfaction will decrease. 
Therefore, companies must learn how to guide customers to participate in value co-creation, be able to understand customers, provide them with different customer participation methods according to customer types, let them play different roles, and design values that suit customer needs according to customers' wishes and knowledge capabilities...

\subsection{Limitations and Future Prospects}

This article uses smart phones as an example to explore the impact of customer participation in value co-creation on their satisfaction. Since the development of smart phones is a highly complex product, it may be willing to participate for people with a high level of knowledge and education, but for a lower level of education. Of people think that participation may be difficult. This article is too singular in the selection of reference objects, and subsequent research can choose other services or products to continue in-depth research and discussion.

\section{REFERENCES}

[1] Wenzhen $\mathrm{Wu}$, Qijie Chen. The influence of customer participation behavior on their satisfaction and behavior intention based on the perspective of co-creating value. Management Review, 2017, 29(09), pp:167-180.

[2] Baiyu Wu, Benhong Peng. Service-dominant logic, network embedding and network platform value co-creation: the mediating role of dynamic capabilities.Research and Development Management,2018,30(1), pp:138-150.

[3] Tao Wang, Haijun Wang. Will Customer Participation Definitely Lead to Customer Satisfaction-The Impact of Customer Selfdiscipline Tendency and Participation Style Consistency on Satisfaction. Nankai Management Review, 2008(03), pp:4-11+19.

[4] Hui Zhang, Tao Wang, Hongshen Liu.Why are customers still dissatisfied after participating? A study on the relationship between control illusion and customer satisfaction in the process of customer participation. Nankai Management Review, 2011, 14(05), pp: 153-160.

[5] Ballantyne D, Varey R J. Creating Value-in-use Through Marketing Interaction: The Exchange Logic of Relating, Communicating and Knowing. Marketing Theory, 2006, Vol. 6, No. 3(3).

[6] Roelens B, Lemey E, Poels G . A service science perspective on business modeling// International Workshop on Value Modeling \& Business Ontology. 2012.
[7] Bendapudi N, Leone R P. Psychological implications of customer participation in coproduction. Journal of marketing, 2003, 67(1), pp: 14-28.

[8] Prahalad CK, Ramaswamy V. The Future of Competition: Co-Creating Unique Value with Customers. Boston: Harvard Business School Press, 2004.

[9] Cova B, Salle R. Marketing solutions in accordance with the S-D logic: Co-creating value with customer network actors. Industrial Marketing Management, 2008, 37(3), pp:270-277.

[10] Nadeem W, Juntunen M, Shirazi F,Hajli N. Consumers' value co-creation in sharing economy: The role of social support, consumers' ethical perceptions and relationship quality. Technological Forecasting \&amp; Social Change, 2020,151.

[11] Sut Ieng Lei, Shun Ye, Dan Wang. Engaging Customers in Value Co-Creation Through Mobile Instant Messaging in the Tourism and Hospitality Industry. 2020, 44(2), pp: 229-251.

[12] Jiayin Liu, WooMi Jo. Value co-creation behaviors and hotel loyalty program member satisfaction based on engagement and involvement: Moderating effect of company support. Journal of Hospitality and Tourism Management, 2020, 43.

[13] Youlin Hu, Qinglan Han. Research on the Impact of Customer Participation on Product Service System Innovation Performance-Based on the Adjustment Analysis of Product and Service Combination. Management Review, 2018, 30(12), pp: 76-88

[14] Ritter T, Walter A.Relationship-specific Antecedents of Customer Involvement in New Product Development. International Journal of Technology Management, 2003, 26(5/6), pp: 482502.

[15] Cragin S.The Determinants of New Product Acceptance in Industrial Channels. Ph.D., the Oklahoma State University, 2003.

[16] Dong Jingjing, Xu Zhengliang, Fang Qi, Han Xiaoyi. The impact of customer interaction in virtual brand communities on product innovation behavior. Technology Economics, 2019, 38(08), pp: $48-54+126$.

[17] Kim J H, Z-T Bae and SH Kang. The role of online brand communities in new product development: Case studies on digital product manufacturers in Korea. International Journal of Innovation Management, 2008, 12(3), pp: 357-376. 
[18] Wang Li, Luo Jinlian.The relationship between customer participation and satisfaction in product innovation: an empirical study based on highcomplexity products. Science Research Management,2012,33(12), pp:1-9.

[19] Grönroos C. A service perspective on business relationships: The value creation, interaction and marketing interface. Industrial Marketing Management,2010,40(2).

[20] Goel A, Yang N. Adopting a service logic in manufacturing.Conceptual foundation and metrics for mutual value creation. Service Management, 2010, 21, pp: $1-6$.

[21] Holbrook MB, Hirschman EC. The experiential aspects of consumption: Consumer fantasies, feelings, and fun. Journal of consumer research, 1982, 9(2), pp: 132-140.

[22] Óscar González-Mansilla, Gloria BerenguerContrí, Antoni Serra-Cantallops. The impact of value co-creation on hotel brand equity and customer satisfaction. Tourism Management, 2019, 75. 